IZA DP No. 6876

Can Taxes Stabilize the Economy in the Presence of Consumption Externalities?

Teresa Lloyd-Braga

Leonor Modesto

September 2012

Forschungsinstitut zur Zukunft der Arbeit Institute for the Study of Labor 


\title{
Can Taxes Stabilize the Economy in the Presence of Consumption Externalities?
}

\author{
Teresa Lloyd-Braga \\ Catolica Lisbon School of Business and Economics \\ Leonor Modesto \\ Catolica Lisbon School of Business and Economics \\ and IZA
}

Discussion Paper No. 6876

September 2012

\author{
IZA \\ P.O. Box 7240 \\ 53072 Bonn \\ Germany \\ Phone: +49-228-3894-0 \\ Fax: +49-228-3894-180 \\ E-mail: iza@iza.org
}

\begin{abstract}
Any opinions expressed here are those of the author(s) and not those of IZA. Research published in this series may include views on policy, but the institute itself takes no institutional policy positions. The IZA research network is committed to the IZA Guiding Principles of Research Integrity.

The Institute for the Study of Labor (IZA) in Bonn is a local and virtual international research center and a place of communication between science, politics and business. IZA is an independent nonprofit organization supported by Deutsche Post Foundation. The center is associated with the University of Bonn and offers a stimulating research environment through its international network, workshops and conferences, data service, project support, research visits and doctoral program. IZA engages in (i) original and internationally competitive research in all fields of labor economics, (ii) development of policy concepts, and (iii) dissemination of research results and concepts to the interested public.
\end{abstract}

IZA Discussion Papers often represent preliminary work and are circulated to encourage discussion. Citation of such a paper should account for its provisional character. A revised version may be available directly from the author. 
IZA Discussion Paper No. 6876

September 2012

\section{ABSTRACT}

\section{Can Taxes Stabilize the Economy in the Presence of Consumption Externalities?*}

Considering a finance constrained economy, we discuss the stabilization role of variable labour and capital income taxes under a balanced-budget rule in the presence of consumption externalities of the "keeping up with the Joneses" type. We find that sufficiently procyclical labor and/or capital income taxes are able to ensure saddle path stability eliminating belief-driven cyclical fluctuations. Moreover, for higher values of consumption externalities, saddle path stability can only be reached with more procyclical labor or capital income taxation. We therefore conclude that finance constrained models with "keeping up with the Joneses" preferences call for traditional Keynesian demand-management policies in order to stabilize business cycle fluctuations.

JEL Classification: E32, E62

Keywords: indeterminacy, consumption externalities, capital and labor income taxation

Corresponding author:

Leonor Modesto

Catolica Lisbon School of Business and Economics

Palma de Cima

1649-023 Lisboa

Portugal

E-mail: Irm@ucp.pt

\footnotetext{
Financial support from "Fundacão para a Ciência e Tecnologia" under the PTDC/EGEECO/103468/2008 is gratefully acknowledged. We wish to thank J.T. Guo for enlightening comments and suggestions. We are also grateful to participants in the PET 2011 Conference, the SAET 2011 Conference and the ASSET 2011 Conference for useful comments and remarks.
} 


\section{Introduction}

Several works have emphasized the destabilizing role of different balancedbudget fiscal policy rules. The typical result, either in standard real business cycles (RBC) models or in the Woodford (1986)/Grandmont et al. (1998) framework, is that countercyclical tax rates on total income (or on labor income) promote indeterminacy, triggering cycles driven by self-fulfilling volatile expectations (sunspots), that would not exist in the absence of government. ${ }^{1}$ Other papers have focused on the properties of fiscal rules that may facilitate the emergence of indeterminacy in the presence of other market imperfections, e.g. externalities. ${ }^{2}$

In contrast, fewer studies adopted the opposite view, i.e., studied under which conditions fiscal policy could eliminate indeterminacy and sunspot fluctuations, in an environment where the latter would prevail due, for instance, to the existence of productive or government spending externalities. The stabilization role of income taxation under a balanced budget rule was first emphasized by Guo and Lansing (1998). They showed that, in a one sector RBC model where indeterminacy was created by increasing returns in production, an income tax schedule exhibiting progressivity can ensure saddle path stability. ${ }^{3}$ Our paper complements and extends their work. We still discuss the stabilization role of variable taxation under a balanced-budget rule, but we consider separately labor and capital income taxes and we use an alternative framework of analysis. Indeed, we extend the Woddford's (1986) finance constrained model, introducing a different type of externalities: consumption externalities. More precisely, we assume that the marginal utility of an individual own consumption increases with aggregate consumption. ${ }^{4}$ This feature is referred in the literature as the desire to keep up with the Joneses. Some authors have analyzed the theoretical impact of this type of externalities on economic growth and optimal tax policy. ${ }^{5}$ However, to our knowledge, this is the first time that the interrelations between 'keeping up with the Joneses' preferences, variable labor and/or capital income tax

\footnotetext{
${ }^{1}$ See Schmitt-Grohé and Uribe (1997) using a Ramsey model, and Gokan (2006) and Pintus (2004) in a Woodford (1986) framework.

${ }^{2}$ See, for example, Gokan (2008) with production externalities and Lloyd-Braga, Modesto and Seegmuller (2008) with government spending externalities in preferences, both in a Woodford's (1986) framework, and Guo and Harrison (2008) in a RBC model with government spending externalities in preferences and production. See also Kamiguchi and Tamai (2011).

${ }^{3}$ See also Christiano and Harrison (1999), Guo (1999) and Guo and Harrison (2004). This last work also introduces fixed capital tax rates.

${ }^{4}$ See Gali (1994.)

${ }^{5}$ See Ljungqvist and Uhlig (2000), Guo (2005) and Wendner (2010).
} 
schedules and macroeconomic (in)stability are analyzed jointly from a policy point of view.

Our framework of analysis is in accordance with empirical evidence and we believe it to be particularly well suited to study policy choices under the current situation of strained public accounts, observed in many developed economies. Indeed, the desire to 'keep up with the Joneses' is not only supported by empirical studies, ${ }^{6}$ but it is also regarded as one of the possible causes behind the increase in consumption and debt that helped to spread the current financial and economic crisis. ${ }^{7}$ Moreover, the Woodford (1986) framework, where workers are finance constrained and save only in the form of money, is closer to the situation existing in most countries, where other assets are held only by a very small fraction of the population. ${ }^{8}$ Note that the financial crisis seems to have exacerbated this feature, increasing the strength of credit constraints. Finally, considering separately labor and capital income taxation is consistent with what we observe in most countries, where tax rules for capital and labor income are different. From a policy point of view it is also important to discuss separately the effects of these two types of taxation, specially within the current economic policy agenda, where countries, forced to reach a balanced budget, are discussing which type of income they should tax and how.

Our main findings are that sufficiently procyclical labor and/or capital income taxes are able to ensure saddle path stability, eliminating belief-driven cyclical fluctuations associated with sufficiently strong consumption externalities. We also find that for higher values of consumption externalities, saddle path stability can only be reached with more procyclical labor or capital income taxation. These findings still hold when we consider total income taxation and are robust to the choice of functional forms and to the parameterizations used. Moreover, when labor(capital) income taxation is sufficiently procyclical saddle path stability can be achieved with flat or even countercyclical capital(labor) income taxes. This last result, which indicates that labor and capital taxation can be seen as substitutable stabilization tools, shows that governments, whose aim is to stabilize the economy, do

\footnotetext{
${ }^{6}$ See for example Carlsson et al. (2003), Ferrer-i-Carbonell (2005) and Mauer and Meier (2008).

${ }^{7}$ See, for instance, Barba and Pivetti (2009).

${ }^{8}$ According to Banks et al. (2000) most american and british households have very few financial assets: median financial wealth in both countries is only a few thousand dollars. Also the top 5\% have more than 50 times the level of financial assets of the median household. In Portugal the 2 highest income deciles own $70 \%$ of total wealth (Alves and Cardoso, (2010)) and for the total population, financial assets (60\% of which are saving deposits) represent only $12 \%$ of net wealth. See IFFS (2010).
} 
have a choice among different combinations of procyclical and countercyclical labor and capital taxation. This is a new result and validates the current policy debate on how the tax burden should be divided between labor and capital income.

Our results concerning the stabilization role of labor income and income taxation reinforce and confirm the insights of most of the research produced so far, according to which (countercyclical) procyclical labor and income taxes tend to promote (in)determinacy. However, our finding that sufficiently procyclical capital taxation stabilizes the economy is novel. This finding, together with those here obtained for labor and total income taxation, show that finance constrained models with "keeping up with the Joneses" preferences call for traditional Keynesian demand-management policies in order to stabilize business cycle fluctuations. ${ }^{9}$

The rest of the paper paper is organized as follows. In the next section we present the model considered and obtain the perfect foresight equilibria. In section 3 we prove the existence and uniqueness of the steady-state. The local stability properties of the model are analyzed in section 4 . In section 5 we discuss the role of taxes as stabilization instruments, providing a robustness and sensitivity analysis of the results. Finally some concluding remarks are provided in section 6 .

\section{The Model}

The model here considered extends the Woodford (1986)/Grandmont et al. (1998) framework introducing consumption externalities and taxation. We consider a perfectly competitive monetary economy with discrete time $t=1,2, \ldots, \infty$ and heterogeneous infinite lived agents of two types: workers and capitalists. Both consume the final good, but only workers supply labor. There is a financial market imperfection that prevents workers from borrowing against their wage income and workers are more impatient than capitalists, i.e. they discount the future more than the latter. So, in a neighborhood of a monetary steady state, capitalists hold the whole capital stock and no money, whereas workers save their wage earnings through money balances. The final good is produced by firms under a Cobb-Douglas technology characterized by constant returns to scale. We introduce consumption externalities in this framework, i.e., we assume that the individual utility of consumption is affected by the current consumption of others. Finally, we

\footnotetext{
${ }^{9}$ According to standard Keynesian models the government should lower (increase) tax rates in bad (good) times in order to stabilize the business cycle, reducing the possible costs of fluctuations. On this issue see also Ljungqvist and Uhlig (2000).
} 
consider "wasteful"public spending, that is financed by labor and/or capital income taxes. The detailed description of the model is provided below.

\subsection{Production}

In each period $t=1,2, \ldots, \infty$, both capital $k_{t-1}>0$ and labor $l_{t}>0$ are used to produce output $y_{t}$ under a Cobb-Douglas technology with constant returns to scale, $y_{t}=k_{t-1}^{s} l_{t}^{1-s}$, where $s \in(0,1)$ represents the capital share of income. From profit maximization, the real interest rate $\rho_{t}$ and the real wage $\omega_{t}$ are respectively equal to the marginal productivities of capital and labor, i.e. $\rho_{t}=s k_{t-1}^{s-1} l_{t}^{1-s}$ and $\omega_{t}=(1-s) k_{t-1}^{s} l_{t}^{-s}$.

\subsection{The Government}

The government chooses the tax policy and balances its budget at each period in time. Therefore, real public spending in goods and services in period $t$, $G_{t} \geq 0$, is given by $G_{t}=\tau_{L}\left(\omega_{t} l_{t}\right) \omega_{t} l_{t}+\tau_{K}\left(\rho_{t} k_{t-1}\right) \rho_{t} k_{t-1}$, where $\tau_{L}\left(\omega_{t} l_{t}\right)$ represents the labor tax rate determined as a function of real aggregate labor income in the economy and $\tau_{K}\left(\rho_{t} k_{t-1}\right)$ represents the capital income tax rate determined as a function of real aggregate capital income in the economy. We assume tax rules a la Lloyd-Braga, Modesto and Seegmuller (2008), i.e., tax rates on labor and capital incomes are determined respectively by the fiscal policy rules:

$$
\begin{aligned}
\tau_{L}\left(\omega_{t} l_{t}\right) & =\mu_{L}\left(\frac{\omega_{t} l_{t}}{\omega l}\right)^{\phi_{L}} \\
\tau_{K}\left(\rho_{t} k_{t-1}\right) & =\mu_{K}\left(\frac{\rho_{t} k_{t-1}}{\rho k}\right)^{\phi_{K}}
\end{aligned}
$$

with parameters $\mu_{i} \in(0,1)$ and $\phi_{i} \in R$ for $i=L, K$, and where $\omega l$ and $\rho k$ are respectively the wage bill and capital income, both evaluated at the steady state. Note that $\mu_{i}$ represents the tax rate at the steady state and that $\phi_{i}$ denotes the elasticity of the tax rate with respect to the tax base. ${ }^{10}$ When $\phi_{i}<0$ the tax rate decreases when the tax base expands, i.e., the tax rate moves countercyclically. The case of $\phi_{i}>0$ corresponds to the case where the tax rate increases with the tax base, i.e. the tax rate is procyclical. For

\footnotetext{
${ }^{10}$ Note that if we had considered more general tax rates functions, instead of assuming an isoelastic specifications as in (1) and (2), our results would not change, provided $\mu_{i}$ and $\phi_{i}$ respectively denote the level of the tax rates and their elasticities with respect to the tax base evaluated at the steady state.
} 
$\phi_{i}=0$ the tax rate is constant at the level $\mu_{i} \cdot{ }^{11}$ For future reference it is convenient to define the following parameters that summarize government intervention in the labor and capital services' markets:

$$
\begin{aligned}
a_{L} & \equiv \phi_{L} \frac{\mu_{L}}{1-\mu_{L}} \\
a_{K} & \equiv \phi_{K} \frac{\mu_{K}}{1-\mu_{K}}
\end{aligned}
$$

As we shall see, the policy instruments $\phi_{i}$ and $\mu_{i}$, for $i=L, K$, only influence dynamics through the parameters $a_{L}$ and $a_{K}$. Note that we obtain $a_{i}=0$, for $i=L, K$, in two different situations, namely when the steady state tax rate is zero, $\mu_{i}=0$, or when the tax rate is constant, $\phi_{i}=0$. Also the sign and the level of $a_{i}$ can be made to vary by controlling the policy instrument $\phi_{i}$ and keeping constant the steady state tax rate $\mu_{i}$. Indeed $a_{i}$ is increasing in $\phi_{i}$ and $a_{i}>0\left(a_{i}<0\right)$ corresponds to $\phi_{i}>0\left(a_{i}<0\right)$, i.e., a procyclical (countercyclical) tax rate.

\section{$2.3 \quad$ Workers}

We introduce externalities in the consumption of workers. Consumption externalities correspond to the idea that the individual utility of consumption is affected by the current consumption of others (envy or altruism), so that aggregate or average consumption becomes an argument of the utility function (Alonso-Carrera et al. (2008), Gali (1994), Ljungqvist and Uhlig (2000), Weder (2000)). Here we assume that individual workers compare their own consumption, $c_{t}^{w} \geq 0$, to the average consumption of workers, $\bar{c}_{t}^{w}$.

The behavior of the representative worker can then be summarized by the maximization of its utility $U\left(c_{t+1}^{w}, \bar{c}_{t+1}^{w}, l_{t}\right) \equiv c_{t+1}^{w}\left(\bar{c}_{t+1}^{w}\right)^{\chi} / B-l_{t}$, subject to the budget constraint $p_{t+1} c_{t+1}^{w}=\left(1-\tau_{L}\left(\omega_{t} l_{t}\right)\right) w_{t} l_{t}=m_{t}$, where $p_{t}$ is the price of the final good and $w_{t}$ the nominal wage at period $t, l$ are hours worked with $l \in[0, \widetilde{l}]$, where $\widetilde{l}$ is the worker's time endowment, $m_{t}$ represents money holdings at the beginning of period $t+1, B>0$ is a scaling parameter and $\chi>0$ is the elasticity of consumption externalities with respect to average consumption. ${ }^{12}$ Note that $\chi>0$ corresponds to the "keeping up

\footnotetext{
${ }^{11}$ This specification nests most cases considered in the literature. For example, the case considered in Gokan (2006), Pintus (2004) and Schmitt-Grohé and Uribe (1997) where a constant amount of public expenditures is financed by proportional taxes corresponds to the case where $\phi_{i}=-1$.

${ }^{12}$ Note that if we had considered a more general multiplicative externality function, our results would be identical, provided $\chi$ denotes the elasticity of this function evaluated at the steady state.
} 
with the Joneses" case, according to which the marginal utility of individual consumption is increasing in $\bar{c}_{t}^{w}$. The linearity in hours worked follows the indivisible labor formulation of Hansen (1985) and Rogerson (1988). ${ }^{13}$ Workers take tax rates and the average consumption of workers as given when solving their maximization problem. ${ }^{14}$ The solution of this problem is given by the intertemporal trade-off between future consumption and leisure: ${ }^{15}$

$$
c_{t+1}^{w}\left(\bar{c}_{t+1}^{w}\right)^{\chi} / B=\gamma\left(l_{t}\right) \text { with } \gamma\left(l_{t}\right) \equiv l_{t}
$$

where $p_{t+1} c_{t+1}^{w}=\left(1-\tau_{L}\left(\omega_{t} l_{t}\right)\right) w_{t} l_{t}$.

\subsection{Capitalists}

The representative capitalist maximizes the log-linear lifetime utility function $\sum_{t=1}^{\infty} \beta^{t} \ln c_{t}^{c}$ subject to the budget constraint $c_{t}^{c}+k_{t}=\left(1-\delta+\left(r_{t} / p_{t}\right)(1-\right.$ $\left.\left.\tau_{K}\left(\rho_{t} k_{t-1}\right)\right)\right) k_{t-1}$, where $c_{t}^{c}$ represents his consumption at period $t, \beta \in(0,1)$ his subjective discount factor, $r_{t}$ the nominal interest rate and $\delta \in(0,1)$ the depreciation rate of capital. ${ }^{16}$ Capitalists also take the tax rate as given. Solving the capitalist's problem we obtain the capital accumulation equation:

$$
k_{t}=\beta\left[1-\delta+\left(r_{t} / p_{t}\right)\left(1-\tau_{K}\left(\rho_{t} k_{t-1}\right)\right)\right] k_{t-1} .
$$

\subsection{Equilibrium}

Equilibrium on labor and capital markets requires $\omega_{t}=w_{t} / p_{t}, \rho_{t}=r_{t} / p_{t}$. Considering that $m>0$ is the constant money supply, at the monetary equilibrium, where $\left(1-\tau_{L}\left(\omega_{t} l_{t}\right)\right) w_{t} l_{t}=m$ in every period $t$, we have $c_{t+1}^{w}=$ $\omega_{t+1}\left(1-\tau_{L}\left(\omega_{t+1} l_{t+1}\right)\right) l_{t+1}$. Therefore:

\footnotetext{
${ }^{13}$ The functional forms chosen simplify considerably the computations without any loss in generality. Indeed, as shown in section 5.3 where we perform some robustness checks, our results are qualitatively, and in same cases even quantitatively, unnafected by these choices.

${ }^{14}$ Since in our framework tax rates depend on aggregate variables (see (1) and (2)) individuals, being atomistic, take tax rates as given. A simar argument applies to average consumption of workers.

${ }^{15}$ The function $\gamma(l)$ corresponds to the offer curve with $\varepsilon_{\gamma}(l) \equiv \gamma^{\prime}(l) l / \gamma(l) \geq 1$ when consumption and leisure are gross substitutes. This implies that the labor supply elasticity at the individual level is positive, i.e., $1 /\left(\varepsilon_{\gamma}-1\right)>0$. In our case, with a utility function linear in consumption and hours, $\varepsilon_{\gamma}=1$ so that the labor supply at the individual labor is infinitely elastic.

${ }^{16}$ We do not introduce consumption externalities into capitalists' preferences because, since they have a log-linear utility function, such externalities would not affect the dynamics.
} 
Definition 1 A perfect foresight intertemporal equilibrium is a sequence $\left(k_{t-1}, l_{t}\right)$ $\in R_{++}^{2}, t=1,2, \ldots, \infty$, that, for a given $k_{0}>0$, satisfies

$$
\begin{aligned}
& {\left[\omega_{t+1}\left(1-\tau_{L}\left(\omega_{t+1} l_{t+1}\right)\right) l_{t+1}\right]^{1+\chi} / B=l_{t}} \\
& k_{t}=\beta\left[1-\delta+\rho_{t}\left(1-\tau_{K}\left(\rho_{t} k_{t-1}\right)\right)\right] k_{t-1} .
\end{aligned}
$$

with $\omega_{t}=(1-s) k_{t-1}^{s} l_{t}^{-s}$ and $\rho_{t}=s k_{t-1}^{s-1} l_{t}^{1-s}$ and where $\tau_{L}\left(\omega_{t} l_{t}\right)$ and $\tau_{K}\left(\rho_{t} k_{t-1}\right)$ are given respectively by (1) and (2).

Equations (7) and (8) represent, respectively, the intertemporal trade-off between consumption and leisure and capital accumulation. They determine the dynamics of this economy through a two-dimensional dynamic system with one predetermined variable, the capital stock $k_{t}$. Indeed $k_{t}$ is a variable determined by past actions. The value of $l_{t}$, on the contrary, is affected by expectations of future events.

\section{$3 \quad$ Steady State Analysis}

Proposition 1 Existence and uniqueness of the steady state: Defining $\theta \equiv 1-\beta(1-\delta)$ and $x \equiv k / l$, the dynamic system (7)-(8) has a unique steady state $(k, l)$ that satisfies

$$
\begin{aligned}
\theta / \beta & =s x^{s-1}\left(1-\mu_{K}\right) \\
l & =\left[(1-s) x^{s}\left(1-\mu_{L}\right) l\right]^{1+\chi} / B
\end{aligned}
$$

Proof. he steady state $(k, l)$ of the dynamic system $(7)$ and (8) is a stationary solution $k_{t}=k_{t-1}=k$ and $l_{t+1}=l_{t}=l$ of these two equations. Therefore, studying the existence and uniqueness of the steady state $(k, l)$ is equivalent to analyze the existence and uniqueness of a solution $(x, l)$, with $k \equiv x l$, of equations (9)-(10). We can easily see that $x=\left(s \beta\left(1-\mu_{K}\right) / \theta\right)^{1 /(1-s)}$ is the unique solution to equation (9). Furthermore, given this value of $x$, there exists a unique value $l=B^{\frac{1}{\chi}}\left[(1-s) x^{s}\left(1-\mu_{L}\right)\right]^{-\frac{1+\chi}{\chi}}$ solving (10).

\section{Local Stability properties}

We first log-linearize the system (7)-(8) around the steady state, obtaining:

$$
\left[\begin{array}{c}
\widehat{k}_{t} \\
\widehat{l}_{t+1}
\end{array}\right]=[J]\left[\begin{array}{c}
\widehat{k}_{t-1} \\
\widehat{l}_{t}
\end{array}\right]
$$


where hat-variables denote percentage deviation rates from their steady-state values and $J$ is the Jacobian matrix of the system (7) and (8) evaluated at the steady state. Its trace and $T$, and determinant, $D$, are given by:

$$
\begin{gathered}
T=1+\frac{1-\theta(1-s)(1+\chi)\left(1-a_{L}\right)}{(1-s)(1+\chi)\left(1-a_{L}\right)} \\
D=\frac{\left(1-\theta a_{K}\right)-\theta(1-s)\left(1-a_{K}\right)}{(1-s)(1+\chi)\left(1-a_{L}\right)}
\end{gathered}
$$

The local stability properties of the model are determined by the eigenvalues of the Jacobian matrix $J$ or, equivalently, by its trace, $T$, and determinant, $D$, which correspond respectively to the product and sum of the two roots (eigenvalues) of the associated characteristic polynomial $Q(\lambda) \equiv$ $\lambda^{2}-\lambda T+D$.

\subsection{Assumptions on the parameters}

As typically done in Woodford economies, we assume that $0<\theta(1-s)<$ $s<1 / 2$, i.e., that the period is short so that $\theta$ is small, and that $s$ is also small. Moreover, since $\theta$ is small, and following Lloyd-Braga, Modesto and Seegmuller (2011), we will also assume that $1-\theta a_{K}>0$ and that $s>$ $\theta(1-s)\left(1-a_{K}\right) /\left(1-\theta a_{K}\right)$. Note that this last inequality, which becomes $s>\theta(1-s)$ in the absence of capital taxation, implies that after-tax gross capital income, $\left[1-\delta+\rho_{t}\left(1-\tau_{k}\left(\rho_{t} k_{t-1}\right)\right)\right] k_{t}$, is increasing with capital as suggested by empirical works. Also in accordance with empirical studies, and following again Lloyd-Braga, Modesto and Seegmuller (2011) we assume that the after-tax wage bill is increasing in labor, which implies $\left(1-a_{L}\right)>0$. All these assumptions are summarized below in Assumption 1 and we consider them satisfied in the rest of the paper.

\section{Assumption 1}

$$
\begin{aligned}
& \text { 1. } s<1 / 2 \text { and } 0<\theta<s /(1-s) \\
& \text { 2. } \frac{\theta(1-s)-s}{\theta(1-2 s)}<a_{K}<1 / \theta \\
& \text { 3. } a_{L}<1
\end{aligned}
$$

\subsection{Analytical Results}

Analytical results are easier to obtain with the support of Figure 1, where we have represented in the plane $(T, D)$ three lines relevant for our purpose: 


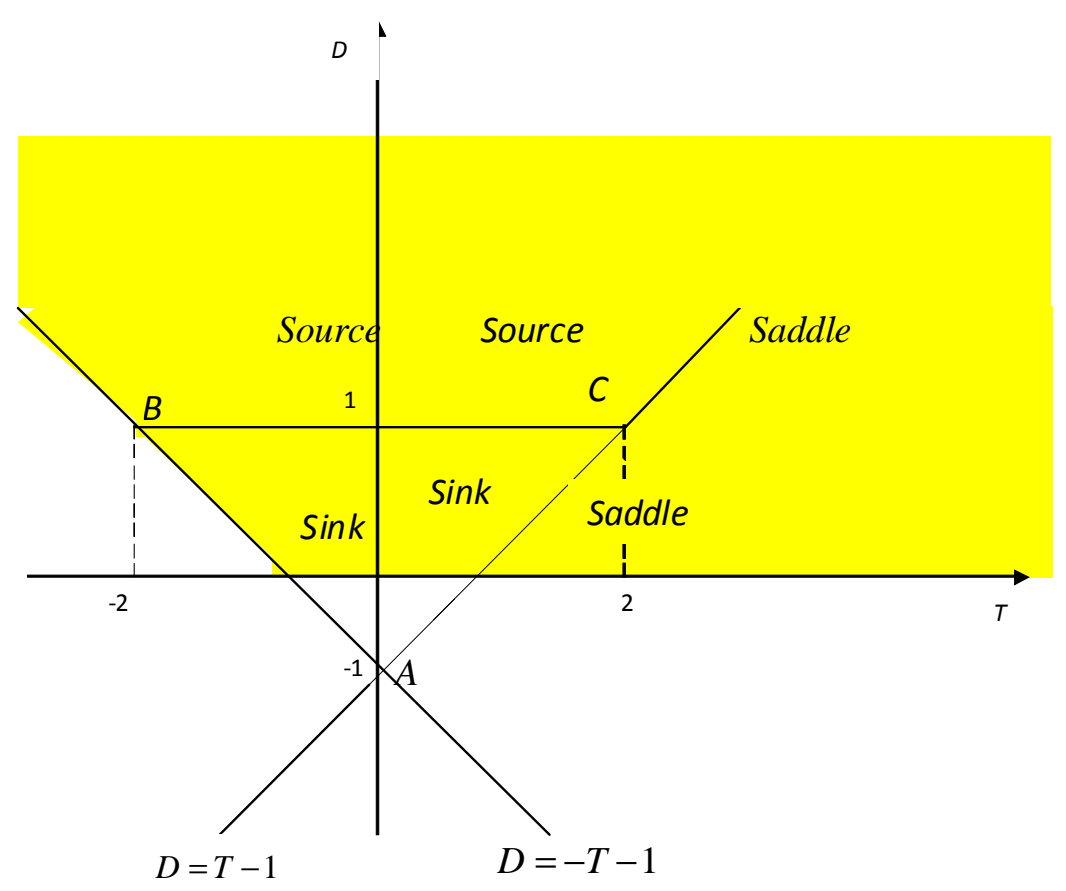

Figure 1: Admissable regions

the line $A C(D=T-1)$ where a local eigenvalue is equal to 1 ; the line $A B(D=-T-1)$, where one eigenvalue is equal to -1 ; and the segment $B C(D=1$ and $|T|<2)$ where two eigenvalues are complex conjugates of modulus 1. When $T$ and $D$ fall in in the interior of triangle $\mathrm{ABC}$ the steady state is a sink (both eigenvalues with modulus lower than one), i.e., asymptotically stable. In this case, given the present context where only capital is a predetermined variable, the steady state is locally indeterminate ${ }^{17}$ and, as known, there are infinitely many stochastic endogenous fluctuations (sunspots) arbitrarily close to the steady state. In all other cases the steady state is locally determinate. It exhibits saddle path stability (one eigenvalue with modulus higher than one and one eigenvalue with modulus lower than one) when $|T|>|D+1|$ and it is an unstable source (both eigenvalues with modulus higher than one) in the remaining regions.

Straightforward computations show that, under Assumption 1, we always have $D>0$ and $D>-T-1$. Therefore only the 3 shaded regions depicted in Figure 1 are possible. We will have a source when $D>\max \{1, T-1\}$,

\footnotetext{
${ }^{17}$ Indeterminacy occurs when the number of eigenvalues strictly lower than one in absolute value is larger than the number of predetermined variables.
} 
a saddle when $D<T-1$ and a sink when $T-1<D<1$. Using (12) and (13) we obtain $D<T-1 \Leftrightarrow a_{K}>a_{K 2}$, and $D<1 \Leftrightarrow a_{K}>a_{K 1}$, with $a_{K 1}$ and $a_{K 2}$ given in the following Proposition:

Proposition 2 Under Assumption 1 and defining $a_{K 1} \equiv \frac{s-(1-s)\left[\chi-(1+\chi) a_{L}+\theta\right]}{\theta s}$ and $a_{K 2} \equiv \frac{(1-s)\left[\chi-(1+\chi) a_{L}\right]}{s}$, we have the following:

- The steady state is a source (unstable) if and only if $a_{K}<\min \left\{a_{K 1}, a_{K 2}\right\}$.

- The steady state is a saddle if and only if $a_{K}>a_{K 2}$.

- The steady state is a sink (indeterminate) if and only if $a_{K 1}<a_{K}<$ $a_{K 2}$.

From Proposition 2 we can immediately see that indeterminacy is only possible if $a_{K 1}<a_{K 2}$. Accordingly we have the following Corollary:

Corollary 1 Under Proposition 2 a necessary condition for the occurrence of indeterminacy is that:

$$
(1+\chi)\left(1-a_{L}\right)>\frac{1}{(1-s)(1+\theta)}>1
$$

A sufficient condition for (14) is that the labor market exhibits the "wrong slopes" condition, i.e., a downward sloping labor supply steeper than the labor demand curve. Although at the individual level we have an infinitely elastic labor supply curve, at the general equilibrium level its elasticity becomes $(1+\chi)\left(1-a_{L}\right) /\left[1-(1+\chi)\left(1-a_{L}\right)\right] \cdot{ }^{18}$ Hence, from (14), indeterminacy requires a negatively sloped labor supply curve. Since the elasticity of the labor demand curve is $-s$, the "wrong slopes" condition $(1+\chi)\left(1-a_{L}\right)>\frac{1}{(1-s)}$ is sufficient for (14). So, once more the emergence of indeterminacy is related with the slopes of the labor demand and supply schedules. ${ }^{19}$

Using also Proposition 2, in the absence of government intervention $\left(a_{K}=\right.$ $\left.a_{L}=0\right)$ we have that $a_{K 2}>0 \Leftrightarrow \chi>0$ and $a_{K 1}<0 \Leftrightarrow \chi>\frac{s-\theta(1-s)}{(1-s)}$. Hence, we obtain the following Corollary:

Corollary 2 Under Proposition 2, indeterminacy occurs without government intervention if and only if $\chi>\frac{s-\theta(1-s)}{(1-s)}>0$.

\footnotetext{
${ }^{18}$ At the general equilibrium level we should take into account that both the labor income tax and average consumption are functions of labor income.

${ }^{19}$ See for example Benhabib and Farmer (1994), Barinci and Chéron (2001) and Dufourt et al. (2008).
} 


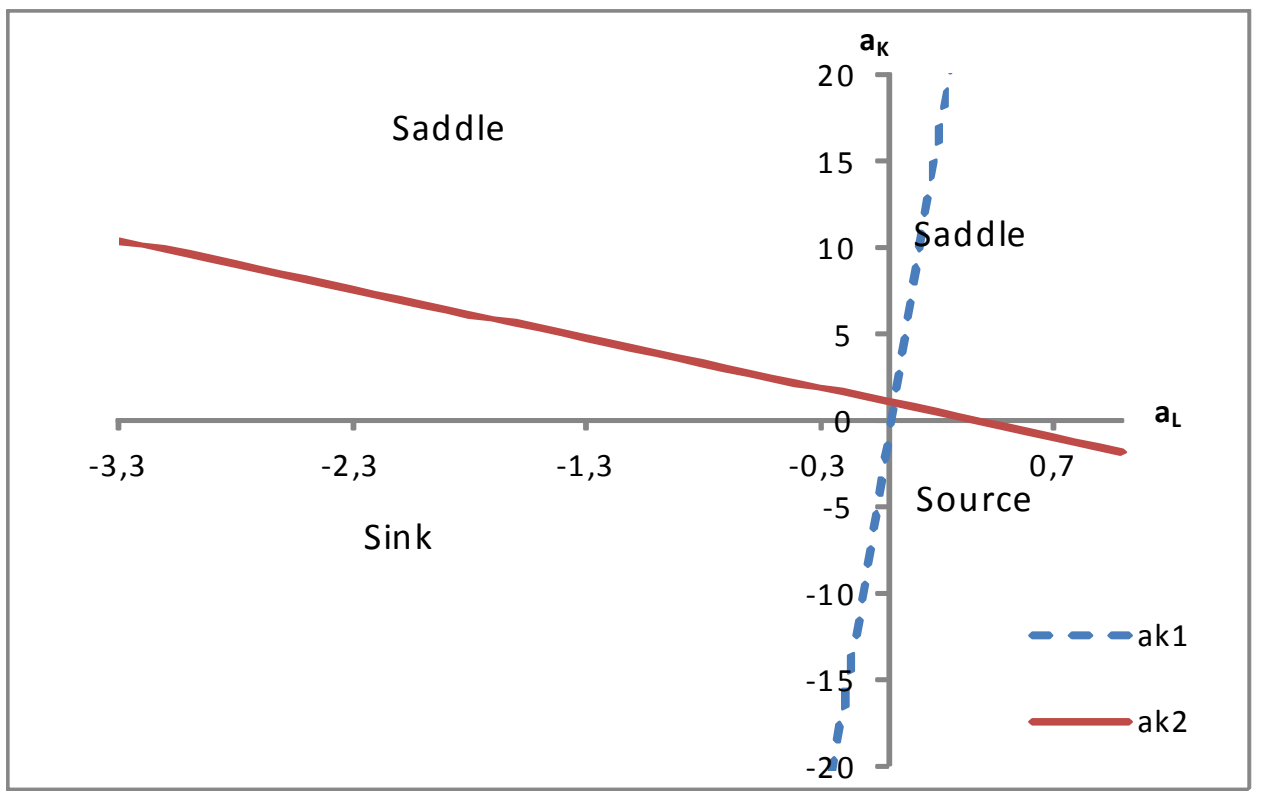

Figure 2: Saddle, sink and source regions

\section{$5 \quad$ Stabilization Policy}

In this section, based on the results obtained in the preceding ones, we discuss the role of taxes as stabilization instruments. We will consider different possible values for $a_{K}$ and $a_{L}$, assuming that $\mu_{K}$ and $\mu_{L}$ are fixed, while $\phi_{K}$ and $\phi_{L}$ vary. $^{20}$

To ease the discussion we have depicted in Figure 2 , in the plane $\left(a_{L}, a_{K}\right)$, the functions $a_{K 2}$ and $a_{K 1}$ given in Proposition 2, that define the sink, saddle and source regions for value of the parameters consistent with Assumption 1 and Corollary 2. We considered $\beta=0.99$ and $\delta=0.025$, in line with most calibrations used in the business cycle literature for quarterly data. Hence, $\theta=0.03475$, and we fix $s=0.35$, so that $\theta(1-s)<s<0.5$, as required by Assumption 1. Also, since in this paper we discuss how tax policy can be used to stabilize the economy, eliminating expectations driven cycles, we fix $\chi=0.52$ a value consistent with the emergence of indeterminacy in the absence of government intervention. See Corollary 2.

The first remark is that for sufficiently negative values of $a_{K}$ and $a_{L}$ the steady state is a sink, for sufficiently positive values of $a_{K}$ and $a_{L}$ the steady state is a saddle and when $a_{L}$ is sufficiently positive and $a_{K}$ is sufficiently

\footnotetext{
${ }^{20}$ Note that $\phi_{K}$ and $\phi_{L}$ do not affect the steady state values of $k$ and $l$. See (9) and (10).
} 
negative the steady state is a source.

The fact that sufficiently positive values of $a_{K}$ and $a_{L}$ ensure that the steady state is a saddle can also be easily shown using Proposition 2 . Indeed this will happen when the condition $a_{K}>a_{K 2}$ is satisfied, which can be written as:

$$
(1-s)(1+\chi) a_{L}+s a_{K}>\chi(1-s) .
$$

Therefore, sufficiently positive values of $a_{L}$ and $a_{K}$ guarantee the emergence of a saddle. Since the steady state is unique, by choosing tax policies that guarantee the emergence of a saddle, the government is able to prevent cycles driven by self-fulfilling volatile expectations (sunspots), stabilizing successfully the economy. Accordingly we have the following Proposition:

Proposition 3 Sufficiently procyclical tax rates on capital and labor income ensure saddle path stability and are able to eliminate indeterminacy caused by positive consumption externalities.

From Figure 2, since $a_{K 2}$ defines, in the space $\left(a_{L}, a_{K}\right)$, a negative relationship between $a_{L}$ and $a_{K}$ for any given value of $\chi>0$, we can also see that when capital income taxes are more procyclical (i.e., the higher is the positive value of $a_{K}$ ) the lower the degree of procyclicality in labor income taxation required to eliminate expectations driven cycles. In fact if $a_{K}>\frac{(1-s) \chi}{s}>0$ we can even obtain a saddle with countercyclical or constant labor income taxes, since in that case condition (15) can be satisfied when $a_{L} \leq 0$. Similarly, when labor income taxes are sufficiently procyclical we can obtain a saddle with countercyclical or constant capital income taxes. Indeed, if $a_{L}>\frac{\chi}{1+\chi}>0$, condition (15) can be satisfied for $a_{K} \leq 0$. These results are summarized in the following Proposition:

Proposition 4 The higher the degree of procyclicality of the capital income tax, the lower the degree of procyclicality of the labor income tax required to guarantee saddle path stability. If the capital income tax is sufficiently procyclical, i.e. if $a_{K}>\frac{(1-s) \chi}{s}$ saddle path stability can even be obtained with a constant or countercyclical tax rate on labor income, i.e., with $a_{L} \leq 0$.

Also, the higher the degree of procyclicality of the labor income tax, the lower the degree of procyclicality of the capital income tax required to guarantee saddle path stability. If the labor income tax is sufficiently procyclical, i.e. if $a_{L}>\frac{\chi}{1+\chi}$, saddle path stability can even be obtained with a constant or countercyclical tax rate on capital income, i.e., with $a_{K} \leq 0$.

This last result is in accordance with Guo (1999) who found that, in a one-sector RBC model with strong increasing returns in production, progressive taxation of labor income can stabilize the economy against sunspot fluctuations, even when the capital tax schedule is flat. 


\subsection{Using only labor income taxation to stabilize the economy}

In this section, labor income taxation is the only stabilization tool considered.

When we only have labor income taxation, $\mu_{K}=\phi_{K}=0$, or when capital income tax rates are constant, $\phi_{K}=0$, we have $a_{K}=0$. Therefore, the condition $a_{K}>a_{K 2}$, which guarantees that the unique steady state is a saddle, becomes:

$$
a_{L}>\frac{\chi}{1+\chi}
$$

Hence sufficiently procyclical labor income taxes are able to stabilize the economy. For example, using our calibration $(\chi=0.52)$, where in the absence of any distortionary taxation indeterminacy emerges, the government, by choosing a $\phi_{L}$ such that $a_{L} \equiv \phi_{L} \frac{\mu_{L}}{1-\mu_{L}}>\frac{\chi}{1+\chi}=0.342$, (i.e. for example a $\phi_{L}>1.5$ for $\mu_{L}=0.19$, a $\phi_{L}>1$ for $\mu_{L}=0.255$ or a $\phi_{L}>0.5$ for $\mu_{L}=0.41$, all of them empirically plausible ${ }^{21}$ ) guarantees the emergence of a saddle preventing expectations driven fluctuations.

Moreover, since $\chi /(1+\chi)$ is increasing in the degree of externalities $\chi>0$, for higher values of $\chi$ stabilization (a saddle) can only be reached with higher (positive) values of $a_{L}$. Hence we have the following Proposition:

Proposition 5 For a higher degree of positive consumption externalities, stabilization (a saddle) requires a more procyclical labor income taxation.

\subsection{Using only capital income taxation to stabilize the economy}

In this section capital income taxation is the only stabilization instrument considered.

When we only have capital taxation, $\mu_{L}=\phi_{L}=0$, or when labor income tax rates are constant, $\phi_{L}=0$, we have $a_{L}=0$. As in the labor taxation case, the government can eliminate fluctuations, guaranteeing the existence of a saddle even if capital income taxation is the only available instrument. In this case, from Proposition 2, the unique steady state is a saddle when:

$$
a_{K}>\frac{(1-s) \chi}{s}
$$

As before, sufficiently procyclical capital income taxes stabilize the economy. To further illustrate this result we use again our calibration $(\chi=0.52)$ where

\footnotetext{
${ }^{21}$ See Mendonza et al. (1994).
} 
in the absence of any distortionary taxation indeterminacy would emerge. In this case, the government, by choosing a $\phi_{K}$ such that $a_{K} \equiv \phi_{K} \frac{\mu_{K}}{1-\mu_{K}}>$ $\frac{(1-s) \chi}{s}=0.9657$, (i.e. for example a $\phi_{K}>1.5$ for $\mu_{K}=0.39$, a $\phi_{K}>1$ for $\mu_{K}=0.49$ or a $\phi_{K}>0.5$ for $\mu_{K}=0.66$ ) guarantees the emergence of a saddle preventing belief driven cycles. Comparing these values with the ones obtained in the case where labor income taxation was used, we can conclude that for the same degree of procyclicality of the tax rule, i.e. for the same $\phi_{i}$, the levels of the tax rate on capital income required to guarantee a saddle are higher than the ones needed in the case of labor income taxation, i.e. $\mu_{K}>\mu_{L}$. This suggests that labor income taxation is more powerful than capital income taxation in promoting determinacy. Another way to state this is by simply comparing (16) with (17). Since under Assumption $1, \frac{(1-s) \chi}{s}>\frac{\chi}{1+\chi}$, the degree of procyclicality needed to guarantee a saddle is greater when we only use capital income taxation than when we only use labor income taxation.

Noticing that $\frac{(1-s) \chi}{s}$ is increasing in $\chi$, we see from (17) that for higher values of $\chi$ a saddle can only be obtained with more procyclical capital income taxation. Hence, Proposition 6 follows:

Proposition 6 For a higher degree of positive consumption externalities, stabilization (a saddle) requires a more procyclical capital income taxation.

\subsection{Robustness and sensitivity analysis}

In this section we show that our results still hold qualitatively (and in some cases even quantitatively) in the presence of more general specifications for technology and preferences, and when we consider income taxes instead of distinguishing between labor and capital income taxation. To ease the presentation we address below these two cases separately. We start with the case of income taxation.

\subsubsection{Income taxes}

In our framework it is very easy to substitute labor and capital income taxes by income taxes. Indeed, in this last case labor and capital income are taxed exactly in the same way, i.e. $\mu_{L}=\mu_{K}=\mu$ and $\phi_{L}=\phi_{K}=\phi$ so that $a_{L}=a_{K}=a \equiv \phi \frac{\mu}{1-\mu}$. Imposing this restriction in (15) the steady state is a saddle when: ${ }^{22}$

$$
a>\frac{\chi(1-s)}{1+\chi(1-s)}
$$

\footnotetext{
${ }^{22}$ This is a necessary and sufficient condition.
} 
Therefore, also in the case of income taxation, tax rates must be sufficiently procyclical to guarantee a saddle. Using again our calibration $(\chi=0.52)$, where in the absence of any distortionary taxation, $a=0$, indeterminacy would emerge, the government, by choosing a $\phi$ such that $a>\frac{\chi(1-s)}{1+\chi(1-s)}=$ 0.253 , (i.e. for example a $\phi>1.5$ for $\mu=0.144$, a $\phi>1$ for $\mu=0.20$ or a $\phi>0.5$ for $\mu=0.33$ all of them plausible ${ }^{23}$ ) guarantees the emergence of a saddle, preventing expectations driven cycles, stabilizing successfully the economy. Accordingly we have the following Proposition:

Proposition 7 Sufficiently procyclical income tax rates promote determinacy and are able to eliminate indeterminacy caused by consumption externalities.

Note that $\frac{\chi(1-s)}{1+\chi(1-s)}$ is increasing in $\chi$. Hence, the required degree of procyclicality increases with the strength of consumption externalities. Accordingly we have the following Proposition:

Proposition 8 For higher values of consumption externalities, stabilization (a saddle) requires a more procyclical income taxation.

Comparing condition (18) with condition (16) since $\frac{\chi(1-s)}{1+\chi(1-s)}<\frac{\chi}{1+\chi}$ we can conclude that the required degree of procyclicality to guarantee a saddle is higher when only labor income is taxed (or when capital taxes are constant) than when total income is taxed. Indeed a procyclical income tax rate implies that both taxes, on labor and on capital income are procyclical (and identical). Hence it is natural that the required degree of procyclicality in total income tax is lower than the one required if only labor or capital income taxes are considered. In fact, comparing condition (18) with condition (17), since $\frac{\chi(1-s)}{1+\chi(1-s)}<\frac{(1-s) \chi}{s}$, we also conclude that the required degree of procyclicality to guarantee a saddle is higher when only capital income is taxed (or when labor taxes are constant) than when total income is taxed.

\subsubsection{General specifications for technology and preferences}

Although in this paper we consider a Cobb-Douglas technology and an infinitely elastic labor supply, sufficiently procyclical tax rates still ensure saddle path stability with more general specifications for technology and preferences.

Denoting by $\sigma>0$ the elasticity of substitution between capital and labor and by $1 /\left(\varepsilon_{\gamma}-1\right)>0$ the labor supply elasticity, both evaluated at

\footnotetext{
${ }^{23}$ See again Mendonza et al. (1994).
} 
the steady state, the trace and the determinant of the Jacobian matrix, in this more general environment become: ${ }^{24}$

$$
\begin{aligned}
T & =\frac{\sigma}{(\sigma-s)(1+\chi)\left(1-a_{L}\right)}\left(\varepsilon_{\gamma}-1\right)+T_{1} \text { with } \\
T_{1} & =1+\frac{\sigma\left[1-\theta a_{K}(1+\chi)\left(1-a_{L}\right)\right]}{(\sigma-s)(1+\chi)\left(1-a_{L}\right)}-\frac{\theta\left[1-s-a_{K}\right](1+\chi)\left(1-a_{L}\right)}{(\sigma-s)(1+\chi)\left(1-a_{L}\right)} \\
D & =D_{1}\left(\varepsilon_{\gamma}-1\right)+D_{1} \text { with } D_{1}=\frac{\sigma\left[1-\theta a_{K}\right]-\theta(1-s)\left(1-a_{K}\right)}{(\sigma-s)(1+\chi)\left(1-a_{L}\right)}
\end{aligned}
$$

We assume $\sigma>s$, so that, under Assumption 1, after-tax labor income is increasing in labor and after-tax gross capital income is increasing in capital. In this case $D>0$ and therefore $D<T-1$ is sufficient to ensure saddle path stability. ${ }^{25}$ Let us consider first the case where labor income taxation is the only stabilization tool considered, i.e., $a_{K}=0$. In this case $D<T-1 \Leftrightarrow$ $\varepsilon_{\gamma}>(1+\chi)\left(1-a_{L}\right)$. Since $\varepsilon_{\gamma} \geq 1$, a sufficient condition for a saddle is that $(1+\chi)\left(1-a_{L}\right)<1$. Therefore condition (16) still guarantees a saddle for any value of the elasticity of substitution between capital and labor $\sigma>s$, and for any positive value of the labour supply elasticity. Note however that, in this more general environment, condition (16) is sufficient but not necessary for obtaining a saddle.

We consider now the case where capital income taxes are the only stabilization instrument considered, i.e., $a_{L}=0$. In this case $D<T-1 \Leftrightarrow$ $\varepsilon_{\gamma}\left[a_{K}(\sigma-(1-s))+(1-s)\right]>(1+\chi)\left[a_{K}(\sigma-1)+(1-s)\right]$. Assuming further that $\sigma>1-s$, saddle path stability is ensured under a procyclical policy $\left(a_{K}>0\right)$ when $\varepsilon_{\gamma}>\varepsilon_{\gamma}^{*} \equiv(1+\chi)\left[a_{K}(\sigma-1)+(1-s)\right] /\left[a_{K}(\sigma-(1-s))+(1-s)\right]$. Since $\varepsilon_{\gamma} \geq 1$, a sufficient condition for a saddle is that $\varepsilon_{\gamma}^{*}<1$. Assuming also that $\sigma<1+\frac{s}{\chi}$, this last condition can be rewritten as:

$$
a_{K}>\frac{(1-s) \chi}{s-\chi(\sigma-1)}>0
$$

Therefore, a sufficiently procyclical tax rate on capital income still guarantees saddle path stability for any $\varepsilon_{\gamma} \geq 1$ and $1-s<\sigma<1+s / \chi$. Condition (17) is recovered from (21) for $\sigma=1$. However, (17) is both a sufficient and necessary condition for saddle path stability when $\sigma=1$ and $\varepsilon_{\gamma}=1$, whereas (21) is only a sufficient condition in this more general environment.

\footnotetext{
${ }^{24} \mathrm{~A}$ Cobb-Douglas technology and an infinitely elastic labor supply correspond to the case where $\sigma=1$ and $\varepsilon_{\gamma}=1$.

${ }^{25}$ Note that in this case indeterminacy emerges if and only if $\chi>\frac{\sigma-\theta(1-s)}{\sigma-s}-1$ and $\sigma>$ $s+\frac{\theta(1-s)}{2}$. When $\sigma=1$ this last condition is satisfied under Assumption 1. Furthermore, if we also have $\varepsilon_{\gamma}=1$, the first condition on $\chi$ becomes the one in Corollary 2 .
} 


\section{Concluding Remarks}

We conclude that procyclical labor and capital income taxes are able to stabilize an economy with consumption externalities, successfully eliminating business cycles due to self-fulfilling prophecies. These findings confirm previous insights about the stabilization effects of procyclical labor income and income taxation. However the result that procyclical capital taxation can also eliminate expectations driven fluctuations is new. Our work therefore rehabilitates the role of capital income taxation as a stabilization tool.

Our results also have policy implications and can be used to comment on recent fiscal consolidation policies. In the current economic crisis, countries of the EU periphery were forced to drastically reduce their public deficits and are strongly advised to keep a balanced budget. Consequently, they have significantly increased tax rates within a recession scenario. Many economic analysts fear that this increase in tax rates will reinforce the crisis and create instability. In this context, the importance of self-fulfilling prophecies is also clearly recognized by policy makers of the European periphery, that are determined to change markets expectations and perceptions in order to restore credibility and confidence. ${ }^{26}$ In fact, according to our model this countercyclical tax policy is problematic, triggering belief-driven cycles. In contrast, our results show that procyclical labor and capital income tax rates eliminate fluctuations due to animal spirits. This is a conclusion with a clear Keynesian flavour.

Our results are robust to the choice of parameterizations and functional forms within a finance constrained economy with consumption externalities. It remains to be seen whether they are still valid in general equilibrium models of the Ramsey type. Previous results seem to indicate that this will be the case but this is clearly a topic for further research.

\section{References}

[1] Alonso-Carrera, J., Caballé, J., and X. Raurich (2008), "Can Consumption Spillovers Be a Source of Equilibrium Indeterminacy?" Journal of Economic Dynamics and Control, 32, 2883-2902.

[2] Alves, N. and F. Cardoso (2010) "A poupança das famílias em Portugal: evidência micro e macroeconómica" Banco de Portugal, Boletim Económico, vol 16, 4, 49-70.

\footnotetext{
${ }^{26}$ See Gaspar (2012).
} 
[3] Banks, J. R. Blundell and J.P. Smith (2000) "Wealth Inequality in the United States and Great Britain", Institute for Fiscal Studies, W.P. $00 / 20$.

[4] Barinci, J.-P., and A. Chéron (2001), "Sunspot and the Business Cycle in a Finance Constrained Model," Journal of Economic Theory, 97, 3049.

[5] Barba, A. and M. Pivetti (2009), "Rising household debt: Its causes and macroeconomic implications - a long-period analysis", Cambridge Journal of Economics, 33, 113-137.

[6] Benhabib, J., and R. Farmer (1994), "Indeterminacy and Increasing Returns," Journal of Economic Theory, 63, 19-41.

[7] Carlsson, F., O. Johansson-Stenman, and P.Martinsson (2003) "Do you enjoy having more than others? Survey evidence of positional goods" Economica 74, 586-598.

[8] Christiano, L. and S. Harrison, (1999), "Chaos, sunspots and automatic stabilizers", Journal of Monetary Economics, 44, 3-31.

[9] Dufourt, F., Lloyd-Braga, T. and L. Modesto (2008), "Indeterminacy, Bifurcations and Unemployment Fluctuations, " Macroeconomic Dynamics, $12,75-89$.

[10] Ferrer-i-Carbonell, A. (2005) "Income and well-being: An empirical analysis of the comparison income effect", Journal of Public Economics 89, 997-1019.

[11] Gali, J. (1994), "Keeping Up with the Joneses: Consumption Externalities, Portfolio Choice and Asset Prices" Journal of Money Credit and Banking, 1-8.

[12] Gaspar, V. (2012), "Portugal: restoring credibility and confidence" Conference delivered by the Portuguese Minister of Finances at the Peterson Institute, Washington, March 19, 2012.

[13] Gokan, Y. (2006), "Dynamic Effects of Government Expenditure in a Finance Constrained Economy" Journal of Economic Theory, 127, 323333.

[14] Gokan, Y. (2008), "Alternative government financing and aggregate fluctuations driven by self-fulfilling expectations" Journal of Economic Dynamics \& Control 32,1650-1679. 
[15] Grandmont, J.-M., P. Pintus and R. de Vilder (1998), "Capital-labour Substitution and Competitive Nonlinear Endogenous Business Cycles" Journal of Economic Theory, 80, 14-59.

[16] Guo, J.-T., (1999), "Multiple equilibria and progressive taxation of labor income" Economic. Letters. 65, 97-103.

[17] Guo, J.-T. (2005), "Tax Policy Under Keeping Up with the Joneses and Imperfect Competition" Annals of Economics and Finance, 6(1), 25-36.

[18] Guo, J.T. and K. Lansing (1998), "Indeterminacy and Stabilization Policy" Journal of Economic Theory, 82, 481-490.

[19] Guo, J.-T. and S. Harrison (2004), "Balanced-budget rules and macroeconomic (in)stability" Journal of Economic Theory, 119, 357-363.

[20] Guo, J. T. and S. Harrison (2008), "Useful Government Spending and Macroeconomic (In)stability under Balanced-Budget Rules" Journal of Public Economic Theory, 10 (3), 383-397.

[21] Hansen, G. D. (1985) "Indivisible labor and the business cycle" Journal of Monetary Economics, 16, 309-327.

[22] INE (National Statistical Office) and Bank of Portugal, O Inquérito à Situação Financeira das Famílias (ISFF), 2010.

[23] Kamiguchi, A. and T. Tamai (2011), "Can productive government spending be a source of equilibrium indeterminacy?", Economic Modelling, 28, 1335-1340.

[24] Ljungqvist, L. and H. Uhlig (2000), "Tax Policy and Aggregate Demand Management under Catching Up with the Joneses" American Economic Review, 90, 356-366.

[25] Lloyd-Braga, T., L. Modesto and T. Seegmuller (2008), "Tax Rate Variability and Public Spending as Sources of Indeterminacy" Journal of Public Economic Theory, 10 (3), 399-421.

[26] Lloyd-Braga, T., Modesto, L. And T. Seegmuller, (2011), "Market distortions and endogenous fluctuations: a general approach", IZA Discussion Paper No. 5603, March.

[27] Maurer, J. and A. Meier (2008), "Smooth It Like the 'Joneses'? Estimating Peer-Group Effects in Intertemporal Consumption Choice" Economic Journal, 118 (527), 454-476. 
[28] Mendoza, E.G., A. Razin and L. Tesar (1994), "Effective Tax Rates in Macroeconomics: Cross-Country Estimates of Tax Rates on Factor Incomes and Consumption" Journal of Monetary Economics, 34, 297323.

[29] Pintus, P. (2004), "Aggregate Instability in the Fixed-Cost Approach to Public Spending" mimeo, Aix-Marseille.

[30] Rogerson, R. (1988) "Indivisible labor, lotteries, and equilibrium" Journal of Monetary Economics 21, 3-16.

[31] Schmitt-Grohé, S. and M. Uribe (1997), "Balanced- Budget Rules, Distortionary Taxes, and Aggregate Instability" Journal of Political Economy, 105, 976-1000.

[32] Weder, M. (2000), "Consumption Externalities, Production Externalities and Indeterminacy" Metroeconomica, 51, 435-453.

[33] Wendner, R., "Growth and Keeping Up with the Joneses" (2010), Macroeconomic Dynamics, 14 (Supplement 2), 176-199.

[34] Woodford, M., (1986), "Stationary Sunspot Equilibria in a Finance Constrained Economy" Journal of Economic Theory, 40, 128-137. 